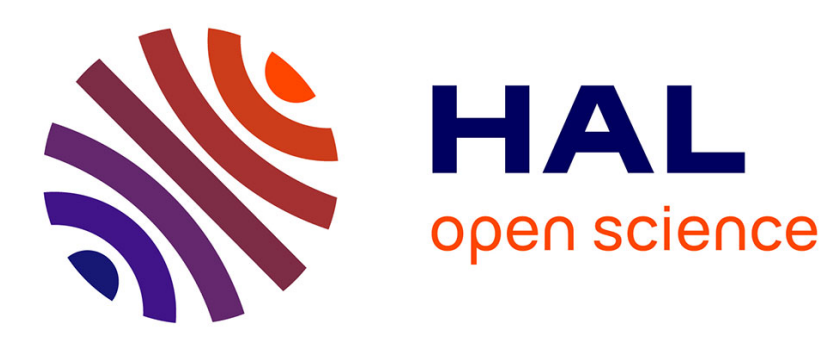

\title{
Learning a Second Language for Specific Purposes within a Hypermedia Framework
}

Thierry Chanier

\section{To cite this version:}

Thierry Chanier. Learning a Second Language for Specific Purposes within a Hypermedia Framework. Computer-Assisted Language Learning, 1996, 9 (1), pp.3-43. edutice-00000123

\section{HAL Id: edutice-00000123}

\section{https://edutice.archives-ouvertes.fr/edutice-00000123}

Submitted on 31 Oct 2003

HAL is a multi-disciplinary open access archive for the deposit and dissemination of scientific research documents, whether they are published or not. The documents may come from teaching and research institutions in France or abroad, or from public or private research centers.
L'archive ouverte pluridisciplinaire HAL, est destinée au dépôt et à la diffusion de documents scientifiques de niveau recherche, publiés ou non, émanant des établissements d'enseignement et de recherche français ou étrangers, des laboratoires publics ou privés. 


\title{
Learning a Second Language for Specific Purposes, within a Hypermedia Framework
}

\author{
Chanier Thierry \\ Laboratoire de Recherche sur le Langage \\ Université Clermont 2, Clermont-Ferrand \\ and Université Paris 5, France. \\ Email: chanier@cicc.univ-bpclermont.fr
}

Chanier T.: Learning a Second Language for Specific Purposes, within a Hypermedia Framework. Learning a Second Language for Specific Purposes within a Hypermedia Framework. Computer-Assisted Language Learning, 1996, 9 (1), pp.3-43.

This paper describes "A la Recherche d'un Emploi", ("Job Hunting") a hypermedia courseware teaching French for Specific Purposes and developed as part of the European CAMILLE project. "A la Recherche d'un Emploi" constitutes an early example of a taskbased and problem-solving oriented software, which interweaves both linguistic and professional goals, on the one hand, and both theoretical knowledge and a hands-on approach, on the other. The paper looks firstly at the common features of the common features of the communicative and LSP approaches in Second Language Acquisition, and at the relevance of the use of hypermedia in the development of learning environments, from a theoretical standpoint. During the presentation of the courseware, our discussion has given rise to several general issues concerned with this type of software and with the more widely used large-scale hypermedia CALL software. These issues included: the relationships between linguistic contents and domain task, simulation activities, authenticity of material, linguistic and cultural resources, follow-up procedures of the learner's performances, etc. The courseware being presented, our attention was then directed to the manner in which the curriculum perspective should be integrated within the development of the CALL environment. Our methodology is explained throughout, from the planning phase and the learner's needs, through to an evaluation of the phase at its termination

\section{INTRODUCTION}

There is some confusion in CALL on programs which claim either to be oriented to Language for Specific Purposes (LSP) or to be built on a communicative approach. The first sort often includes programs which are reduced to sets of vocabulary drills on technical texts. When communicative competence is also mentioned, it is reduced to vocabulary proficiency. The second sort of program is usually based on hypermedia data. The availability of audio, video and texts resources seems to guarantee that language practice is achieved in a communicative way, provided that the data are authentic technical documents. These CALL environments mainly support access to multimedia specialized databases. However even if these environments do represent useful tools, set aside on-line access to large-scale corpora, they cannot be considered as actual learning environments. 
Indeed language learning for specific purposes is an interesting context in which to adopt a communicative approach; and endowing the computer of audio, video, and textual resources is a necessary condition for the building of activities that can help the practice of various competencies mobilized in communication. One way to articulate these activities is to integrate them within a task oriented situation; we then produce a learning environment which is problem-solving oriented.

This paper firstly discusses, from a theoretical standpoint, the common features of the communicative and LSP approaches in Second Language Acquisition (SLA), and the relevance of using hypermedia to develop learning environments. We then present "A la Recherche d'un Emploi" (ARE) as an illustration. The ARE program is the first module of the French for Specific Purposes course, called "Travailler en France". It has been developed in Clermont-Ferrand and immerses intermediate or advanced learners of French into the problem of looking for a job in France. It is based on a hypermedia environment, jointly set up by the partners of the European project CAMILLE1.

Section 3 details the contents and organization of ARE and gives an example of a new kind of activity based on simulation. Section 4 analyses linguistic and domain expertise, pedagogical principles and a learner's interaction and assessment. Section 5 questions the usefulness of complementing the core of the software with lexical, grammatical, functional and socio-cultural resources. In the course of the ARE presentation, we raise several general issues which concern LSP software based on a communicative approach and, more widely, large-scale hypermedia CALL software.

Having discussed the CALL environment, we turn, in section 6, our attention to the curriculum perspective. Our methodology of work is exposed in order to gain insight into the integration of needs analysis, implementation and evaluation in the same project.

\section{PEDAGOGICAL/THEORETICAL PRINCIPLES}

Before revealing the main characteristics of a hypermedia environment for LSP within a communicative approach, we examine its three basic notions: communicative competence, LSP learning situation, and hypermedia environments.

\subsection{THE COMMUNICATIVE COMPETENCE}

One of the most interesting benefits of the work undertaken by theoreticians of the communicative approach (Hymes 1971; Canal \& Swain 1980; Brumfit \& Johnson 1979; Moirand 1982) is their definition of communicative competence. It is now well accepted among researchers and practitioners in Second Language Acquisition (SLA) that being proficient in a language cannot be reduced to mastering a grammatical competence but, because language is intertwined with communication, communicative competence should also be acquired. Among several alternative definitions of the notion of communicative

\footnotetext{
${ }^{1}$ CAMILLE (which stands for Computer-Aided Multimedia Interactive Language Learning Environment) is partly financed by the LINGUA Programme. The current members of the CAMILLE Consortium are the University of Teesside, Middlesbrough, England ; Université Blaise Pascal and Université d'Auvergne, Clermont-Ferrand, France ; Haages Hogeschool, The Hague, Netherlands ; and Universidad Politecnica, Valencia, Spain.
} 
competence let us mention one of the most general (Bérard 1991). Communicative competence includes:

- The formal/grammatical competence: ability to produce and understand correct syntactic, lexical, and phonological forms in a language. This competence is often also called the 'linguistic' one, but it then implies a very narrow interpretation of the coverage of linguistics. Among others, discourse analysis and social aspects of language have always been topics of research for many linguists (see (Hallyday 1973) or (Melrose 1991) for a recent application to language teaching).

- The sociolinguistic/sociocultural competence: ability to use a language appropriately in sociocultural contexts; knowledge of cultural history and relationships among social actors.

- The discourse competence: ability to understand and produce discourses organized in different ways depending on the parameters of the communicative situation (oral/written discourse, academic letter vs. postcard, etc.).

- The referential competence: knowledge of experiential domains, of their objects and relationships; ability to find the corresponding information.

- The strategic competence: ability to effectively transmit information to a listener, including the ability to use communication strategies (Bialystok 1990), and to solve problems which arise in this process.

\subsection{THE SITUATION WHEN LEARNING A LANGUAGE FOR SPECIFIC PURPOSES}

LSP is a very good situation in which to apply the communicative approach because training intertwines linguistic and professional goals, on the one hand, and knowledge and know-how, on the other hand (Rakotobe 1992). When learning a language for specific purposes, none of these competencies can be omitted. If we consider for example our domain, French for business, the learner needs to know a professional vocabulary ; how to access new information in the French business world ; how to use that communicative competence, competence partly based on paralinguistic knowledge (such as behavior, and gestures), to efficiently achieve a professional task. Socio-cultural competence is not an extra but a necessity. A lack of sensibility to cultural differences between natives and non-natives often leads to a serious degradation in the communication process as well as failures in professional relationships.

Besides the kind of knowledge involved in language learning, the nature of learning itself is of great importance to pedagogy. Researchers such as Hutchinson and Waters (1987) claim that the LSP approach is appropriate to language learning because of its very nature: language learning is a decision-making process, not just as a matter of linguistic knowledge (the learner is a specialist in his/her own field) ; to support language learning one needs to rely on the learner's first language experience (s/he is already a language user in his/her source language when applying for a job) ; language learning is partly incidental (language can be learned when solving technical claims with a consumer, i.e. not when solving a language problem as such).

The latter remark is of much consequence for course developers (Lehmann 1993): the task is first designed, then linguistic activities will derive from this material rather than prevail. Contrastingly the traditional way of developing audio-lingual and (formerly) communicative courses was to produce lists of items to be divided into structural, notional or 
functional categories, to grade them according to difficulty, frequency or convenience and fit them onto a support. Here, the list of items to be taught becomes a mere checklist, which may even be ignored by LSP course designers. The task chosen needs to be based on authentic documents and set in a pseudo-authentic situation. These felicity conditions are hard to satisfy because teachers are not professionals, i.e. experts in the professional domain where the task is applied. Moreover, authenticity is a controversial point because the real world communication does not exist in language training institutions. It is only artificially recreated for pedagogic purposes.

The pressure for building a learner-centered curriculum, as recommended by SLA research (Tarone \& Yule 1989; Nunan 1988) is stronger for LSP than for a General course: communicative needs are clearly elicited (they are the results of a negotiation between the learner, the employer and the training institution) and, most importantly, the learner is aware of his/her needs. Learning styles are to be taken into account when designing a course. Adults may reject a course which is too tutor-based and await some degree of freedom (at least when they have an intermediate or advanced level). Time is also an important factor for the learner. The duration of the training period has to be limited. Such constraints put forward the question of explicitly teaching various ways of learning, and making explicit learning strategies (0'Malley \& Chamot 1990). Duration is one aspect of the time constraint; professional activities and training sessions are not so easy to time-table. Some flexibility in the curriculum helps solve this problem. A way of increasing flexibility is to offer self-access in training resources. This extra resource would also supplement the limited time span in which some immersion in L2 happens: duration of exposure to the target language is one of the most important discrepancies between L1 and L2 acquisition and this stands however efficient the teaching methods used. Cost and time constraints limit the extent of human trainers' interventions.

After having commented upon some key aspects of the communicative and LSP approaches, we can now see to what extent a hypermedia environment can support L2 LSP learning, i.e. whether they can only be seen as accessory tools, or whether they represent a substantial part of the training. In this discussion we must insist on the fact that our working hypotheses do not include any commitment to the "strong" communicative or LSP approach: we do not claim that L2 acquisition should start ab initio within an LSP perspective, nor that every aspect of L2 should be acquired through communication; neither do we disregard the formal competence nor the drills-and-practice methods.

"Travailler en France" is a course for intermediate/advanced learners of French. Learners should have passed or have the equivalent level of the 4th units of the DEFL (international diploma of elementary French language), which entails a satisfactory degree of proficiency of the French linguistic system (in phonetics, prosody, morpho-syntax) in oral and written skills. Units 5 and 6 of the DEFL, which we try to cover substantially with "Travailler en France", focus on culture and civilization and specialized communicative skills.

\subsection{HYPERMEDIA ENVIRONMENTS}

'Hypermedia' is a term so widely used in CAL (La Passardière \& Baron 1991) that it has become somewhat clouded over. We explain the CAMILLE consortium standpoint on the use of this term and of related concepts. 
First, there is the concept of multimedia. These days 'multimedia' means many things to many people. For the purposes of this article, however, multimedia should be taken to mean a computing resource capable of displaying textual data, graphical data (still or animated), photographic data (still or moving), and of recording and playing back sound data. These various data types may be displayed simultaneously or sequentially depending on the needs of the resource, but it seems likely that the larger-scale systems will want to provide multiple data windows and that these windows may be capable of displaying differing sorts of data.

How this data is accessed, however, leads to the second important concept, hypertext (McAleese \& Green 1990). 'Hypertext' refers to a system of accessing textual data in which the data is understood to be stored in no particular sequence. The data must, of course, be stored in an orderly manner, which is not intended to influence the order in which it is accessed. Ultimately, of course, the data is accessed sequentially, but the sequence is determined by the end-user rather than by the original author. As such, hypertexts are usually understood to be very open data structures which the user is 'free' to explore at will. If you combine the 'openness' of hypertext with the data richness of multimedia you get what is sometimes called hypermedia. That is, you get a media rich data environment in which you can freely move from pictures, to video, to sound, to text or any combination of these in a sequence which you, the user, determine.

One of the great advantages of such systems is that they allow the user to follow their own trains of thought, clarifying issues as they occur to the user rather than as they occurred to the originators. More traditional CALL systems tend to be based on a 'programmed learning' approach. They are structured in a 'tree-like' manner in which progress through the lesson is determined by the choices a learner makes at any given moment. Each choice sends the user down a particular 'branch' of the information available and excludes them from all others. They may, of course, retrace their steps along their chosen path and then choose another, but while they are on one path they cannot easily access information that is contained on other branches of the 'knowledge tree'. This means that the lesson planners or programmers have to ensure in advance that the learner has already acquired all the information s/he needs to make each new choice. Unfortunately in any knowledge domain as complex as language it is virtually impossible to plan in advance for all eventualities.

In 'hyper' information systems, this is unnecessary because the user can move from any point in the system to any other whenever s/he wishes. Accordingly, if, for example, a learner needs to refresh his/her knowledge on some grammatical point before making a particular decision s/he can, in principle move directly to the required information and then back to the point of choice. However, this freedom of movement, or navigation as it is often called, poses its own problems -- most commonly the problem of disorientation. As a user pursues his/her train of thought and one question leads to another they may easily lose sight of the original question and become confused or disillusioned. To understand the potential severity of this problem in educational terms, giving a person 'free' access to a large hypermedia data base would be rather like taking a student to the library and telling them to get an education. The persistent might, but the others...?

Countering this problem has been a major issue for educational courseware developers (see chapters 3, 8, 12 and 13 of McAleese's book), and most developers of educational courseware, seem to have devised solutions similar to those developed in CAMILLE. On the one hand, great care is taken to 'sign-post' the user's current position and relate it to some 
specific 'central' location; and, on the other hand, data resources are not presented as homogenous. The data are commonly divided into 'lesson materials' and 'reference materials'. In the case of CAMILLE, for example, the lesson materials take the form of several dozens of hours of multimedia exercises and other activities that are both highly structured (we adopted a hierarchical structure for the lesson materials) and highly interactive; while the 'reference materials' include culture, function, grammar and lexicon books, and a variety of other reference 'books' all of which are accessible at any moment during the users interaction with the system (see figure 2).

\subsection{HYPERMEDIA ENVIRONMENT FOR LSP WITHIN A COMMUNICATIVE APPROACH}

A paper by Laurillard (1991) states that "communicative teaching methodology prevalent in classroom teaching now is unlikely to meet all learner's needs" and then exposed various principles for computer-based software design for language learning. All of these principles referred to the practice of formal competence with systems that should interact explicitly with the learner about his/her own system of rules, support her/him for abstracting meta-linguistic knowledge from the context of utterances, and match the discrepancies with the native's system of rules. Such systems, which could process intelligent diagnosis of the learner's productions, are certainly a good niche for CALL because it will offer a kind of interaction that teachers and trainers are unable to practically create in institutional settings. Some most complex but promising research has been undertaken by CALL developers interested in combining artificial intelligence, natural language processing techniques and psycholinguistic concerns (see (Chanier \& al 1992 ; Chanier 1994)).

But we should not abandon the niche that CALL communicative systems have established by complementing teacher's interventions and/or by offering self-training. In such systems Laurillard's principles cannot apply and may even be conflicting with the learning principles previously mentioned. For example, Laurillard presented the 'disembedding principle' which implies a decontextualisation of the communication, and partly justifies it on the fact that embedding is weak because it "takes place in an artificial context in the classroom [and] normal motivation to convey and interpret meaning is lost" (Laurillard 1991, p. 147). But if we think that speaking a second language means mastering the communicative competence, including all types of competencies mentioned, it must also mean trying to practice them all; whatever the limitations in institutional settings are. Discourse competence, for example, cannot be decontextualised: being able to interpret a discourse means being able to satisfy interpretative constraints imposed by the context of the discourse ; and being able to participate to the interaction (i.e. react to a piece of discourse) means being able to satisfy the reaction constraints imposed by the previous part of the discourse. Training learners to acquire discourse competence requires first that trainers/teachers are proficient in discourse analysis (Hatch 1992) and apply it to the kind of interaction that happens in institutional settings (the study of classroom/institutional interaction becomes nowadays an area of research in SLA (Allwright \& Bailey 1991)).

As far as computer environments are concerned, interaction may happen within a taskoriented approach which is a necessary condition for providing a communicative situation:

$<<[. .$.$] Fluency in communicative process can only develop within a 'task-oriented$ teaching' - one which provides 'actual meaning' by focusing on tasks to be mediated through language, and where success or failure is seen to be judged in terms of whether or not these tasks are performed >> (Johnson 1979, p 200) 
A way of applying Johnson's statement is to build a CALL course around one main task, corresponding to LSP needs, and to provide the software with the knowledge bases and activities that can allow the learner to fulfil the task. Thus, knowledge and procedures immersed in a socio-cultural context determine the architecture of the software. Linguistic knowledge and activities will then be designed from the task context, but will not have top priority (see figure 1). Some linguistic activities may be specifically created to let the learner systematize his/her competence and apply it in other situations (at this stage we may fulfil the disembedding principles recalled by Laurillard).

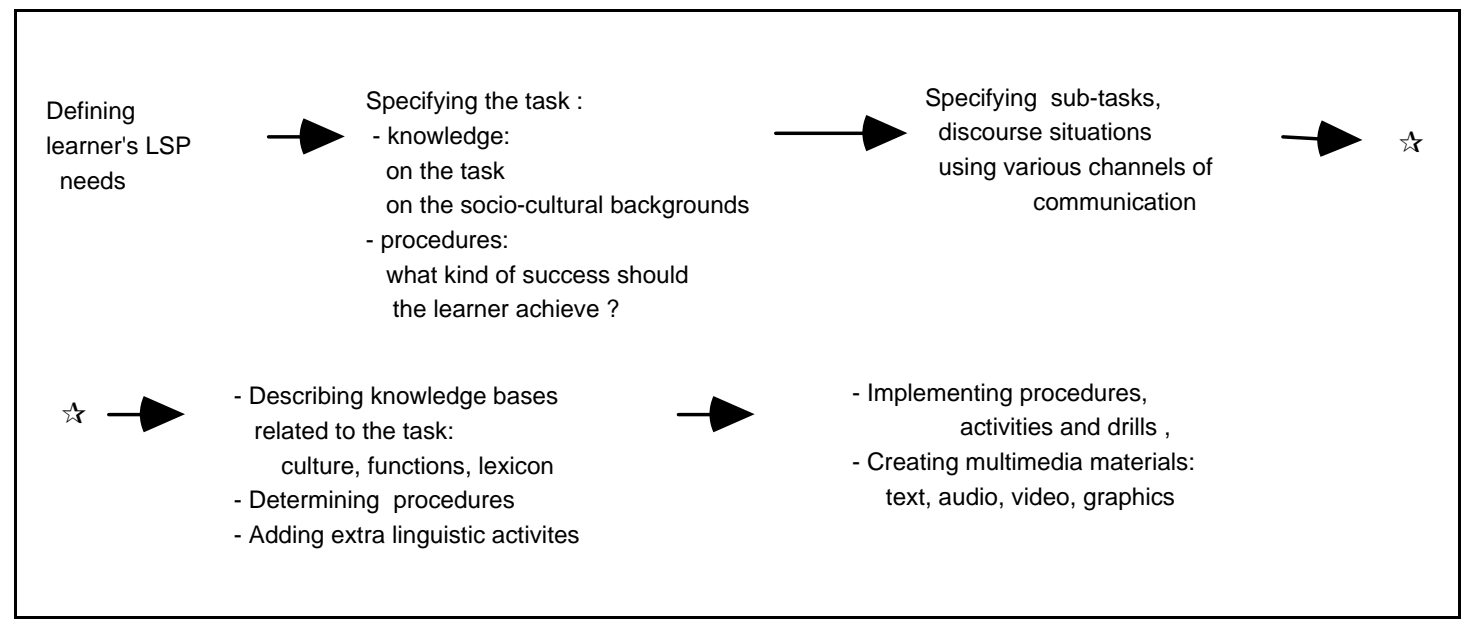

Figure 1: Procedure for creating a LSP hypermedia course

Given this perspective, supporting communicative goals means immersing the learner in a problem-solving situation, where he can access relevant knowledge and interact with the system to solve problems where the vocational goals have been elicited. Assessment is mainly based on the learner's rate of success/failure to achieve the tasks and secondarily on his/her practice of specific linguistic activities. Since language plays a prominent role in the task, the system is able to assess his/her communicative competence. Like many artificial intelligence applications, knowledge bases of different kinds should be made accessible for solving the problem. However it is still too early to seek delivering CALL courses based on a system that would have the ability to solve per-itself the problem (which is one of the AI hypotheses) $)^{2}$.

\section{3. "A LA RECHERCHE D'UN EMPLOI" : OVERVIEW}

"A la Recherche d'un Emploi" is the first module of the French for Specific Purposes course developed in Clermont-Ferrand. Module 2, currently under development, focuses on the selling act. Students of Economics departments and employees of SME constitute the target audience. The hypermedia environment is shared by all CAMILLE partners. Many design principles, relating to the interface, the management of hypermedia resources and interaction with the learner, are common to our consortium (Ingraham \& al 1994). But whereas our Dutch, English and Spanish colleagues produce general level courses in Dutch, French or Spanish, we, in France, are oriented towards specific purposes. In the following we detail the

\footnotetext{
2 Nowadays prototypes do exist of systems which let the learner freely type expressions and also interact graphically, systems which have a restrictive linguistic coverage but real communicative abilities (see the immersion approach of Hamburger (1994)).
} 
contents and organization of the first module of "Travailler en France" and then give an example of an activity based on a simulation.

\subsection{CONTENTS, ORGANIZATION AND INTERFACE}

Knowing how to look for a job in a foreign country was one of the first learner needs extracted from our inquiry (see details in section 6). The story line of the module is built around two characters who are very different in nature and representative of situations subsequently encountered: Catherine, a young woman of 25, single, postgraduate, has just achieved a work placement abroad, and is seeking a position as international business assistant ; Gérard, 38, has 2 young children and is a technician, made redundant from a printing business 18 months ago, has just achieved a work experience in computer-assisted building design, training sponsored by the ANPE ${ }^{3}$. The task of making a job application has been divided into four subtasks, materialized as separate units (unit 5 is a rehearsal), which are themselves divided into activities:

- Unit 1: where to find appropriate information and acquire backgrounds on the employment market. Both Catherine and Gérard's situations are introduced through video interviews. Then follow activities on the comprehension of their stories and CVs, on identification of discourse markers and on job vacancies. In the latter the learner has to find adverts in newspapers relevant either to Catherine or Gérard.

- Unit 2: how to write letters of application and CVs in the French way. First, the learner is presented with the usual formats of formal correspondence/letters, specific formulae varying with the socio-cultural context; s/he has then to identify functions of given letters; eventually to compose a letter of application for Catherine. The second part of the unit relates to CVs and is structured around the same format: graded activities involving, at the beginning identification of data, and at the end (constrained) composition. Although unit 2 is mainly text oriented, video is used to display an extra part of Catherine's interview, and from which elements can be extracted to then include in her $\mathrm{CV}$.

- Unit 3: how to fix an appointment using a telephone. A video shows Catherine at home while returning a call to the staff manager of a company where she had sent a jobapplication. The learner can then work on the telephone sublanguage, on figures around which oral activities have been designed. Lastly s/he can play a simulation: on behalf of Catherine, s/he tries to clear the obstacles to obtain by the telephone an appointment with another staff manager, depending on the way s/he behaves s/he may succeed or fail. - Unit 4: how to manage an interview. Activity one outlines the main topics tackled in an interview and relates them to typical questions used by both applicants and recruiters in an interview environment. In the next activity, several facets of the applicant's behavior are illustrated (clothes, looks, gestures, etc.) and the learner has to recount (by typing) for a friend what to do (or avoid doing) in a given situation. Activity 3 is organized around ways of talking about his/her own positive/negative qualities. Having achieved this preparation, the learner can then run the simulation of the last activity, where s/he may take the role of either Catherine or Gérard by participating in the interview (this activity will be detailed later on).

${ }^{3}$ ANPE (Agence Nationale Pour l'Emploi) is the national institution that is in charge of helping people to find work. 
Figure 2 displays the contents of unit 2 and illustrates the typical hierarchical structure shared by of all CAMILLE modules. It is recommended to undertake sequential activities located on the same branch. Parallel branches symbolize disjunctive sets of activities. All screens share similar aspects, in order to keep some homogeneity and coherence at the level of the machine-user interface:

- In the top left corner of the window, are indications allowing the user to locate himself easily.

- In the top right corner, are AIDE and INSTRUCTION buttons. When the first one is pressed general maps appear and recall the function of every button (including control video and audio panel), functionality of mouse buttons, and important key-board control buttons (used to select, copy and paste). The second one gives access to a text and audio window and reminds the learner what s/he should do next. This is a repetition (sometimes more detailed) of the oral message which s/he has heard when entering a new page.

- At the bottom of the screen a row of buttons gives access to resources or procedures (icons displaying a graph or arrows) to move around in the hypertextual structure of the module : move up to the top module screen ; up to the first mother node ; forward or back to sub activities at the same level. When a function is not available, the corresponding button becomes grey.

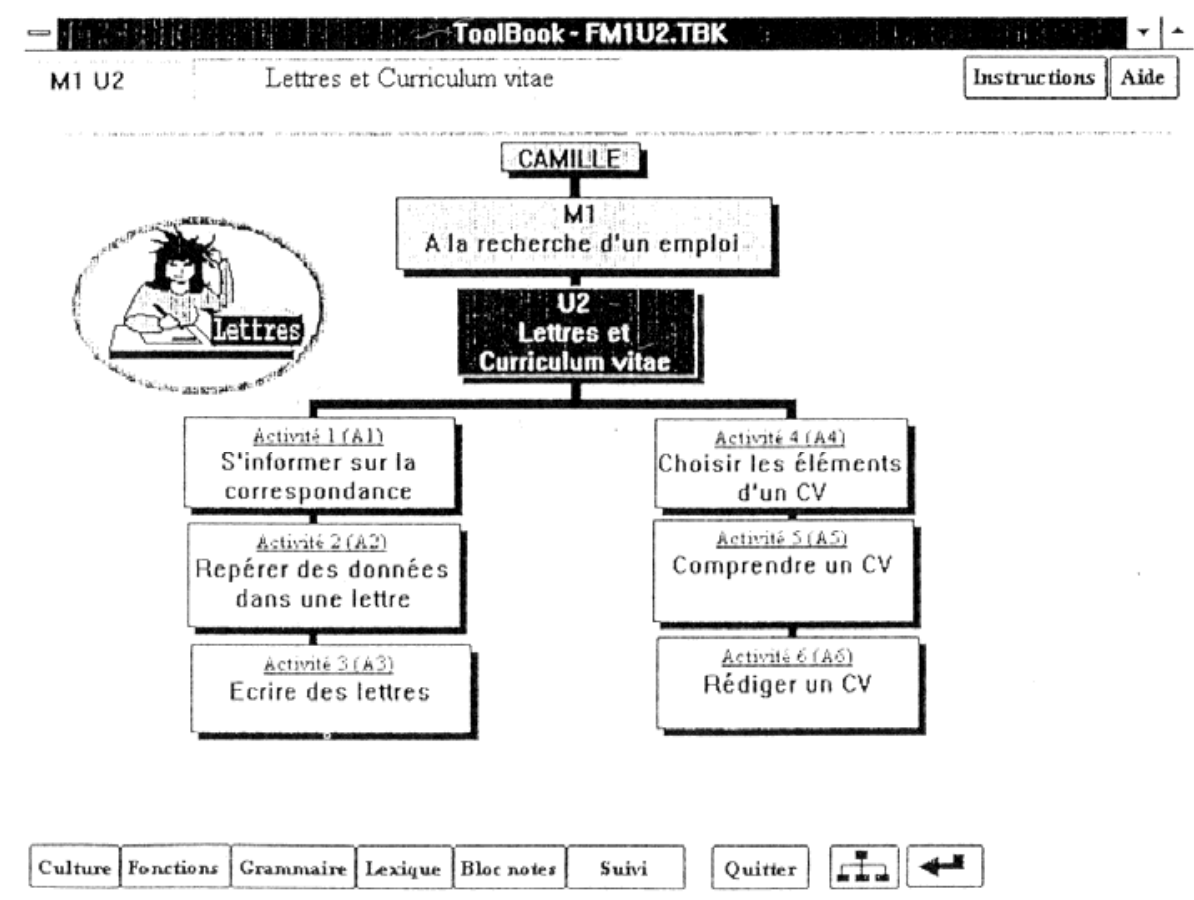

Figure 2: A typical screen displaying common features of the interface and unit contents (here Unit 2).

"A la Recherche d'un Emploi" has been conceived, as well as all CAMILLE programs, as a self-contained course. Accordingly, when the user enters the environment, the screen s/he encounters may be understood as representing a desktop on which a textbook lies open at the table of contents. Surrounding this textbook are button icons for moving around the textbook, for giving help and instructions, the system's evaluation of the learner's performances, and for accessing books/resources: grammar, a lexicon, a book about French culture, a book about linguistic functions, and a notebook for the user to record whatever s/he 
wishes. From this 'desktop' the student may move to any point in the textbook by selecting the appropriate item in the table of contents, or they may choose to open any of the reference sources. Since the object of these 'hyper'- reference books is to supply the user with information on demand, it may be accessed at any time during the course. When the user selects one of the reference sources, it is opened as a separate window of information on the desktop. All the reference books may be open at the same time without completely covering the textbook, but the result is a pretty cluttered desk. Keeping the textbook in view is important, because it not only provides the bulk of the user's' activity, but also helps to maintain their orientation in this information 'hyperspace'.

\subsection{DETAILS OF AN ACTIVITY: SIMULATION OF AN INTERVIEW}

Before opening discussions on linguistic, pedagogical and computing aspects of "A la Recherche d'un Emploi" in the next sections, we first need to detail the simulation activity. This will give the reader a precise image of the way we exploit the resources of a hypermedia environment to assist LSP learning on communicative grounds.

Whereas most activities are subdivided into several sub activities and exercises, the two simulations ('on the phone' in Unit 3 and the interview in Unit 4) are not. Since we try to roughly balance the learner's workload among every unit, simulations do require a sustained attention and deep involvement from the learner's point of view.

The learner is invited to play the role of an applicant (either Catherine or Gérard). S/he will only see the video displaying the recruiter's behavior and will have to choose, on every exchange, a written answer among a set of two or three possibilities presented in alternative fields. S/he has two simultaneous tasks to accomplish: firstly, to solve as best as s/he can the problems set during the interview by taking into account the evaluation criteria of the recruiter and the applicant's own objectives ; secondly, to pronounce the selected answer with the right intonation. Before recording her/himself, the learner can listen to the corresponding utterance recorded by the natives who take the place of Catherine or Gérard.

The activity includes five steps:

- 1) the learner reads information describing Catherine and Gérard's situations and chooses a role.

- 2) The system displays the recruiter's criteria and the applicant's objectives; every parameter is assigned to an initial value.

- 3) The learner runs the dialogue.

- 4) At the end of it, the system reveals the new parameters values besides initial ones.

- 5) the learner can then decide either to quit, or to replay the whole previous dialogue without any interruption with her/him recording or with the native's voice, or decide to redo a different dialogue.

In the second step the learner has to fathom meaning and implications of criteria. Every selected answer during the dialogue will be evaluated with respect to them. When undergoing an interview the applicant needs to be aware of which aspects of his/her behavior will be judged primary; and at the same time s/he should not forget what his/her own goals are.

When starting the game every character has his/her set-backs, corresponding to his/her history, which are symbolized by the low values assigned to the criteria. The values are 
performance, as well as the set of topics discussed in the interview (topics, such as wages negotiations, may be skipped accordingly to learner's wrong choices). Several kinds of linguistic communicative competencies are practiced by the learner: formal competence when the learner understands nuances which can discriminate an applicant's answers ; discourse and strategic competence, when s/he follows up the shift of focus in topic, guesses the recruiter's covered intentions or tries to take the initiative of a turnover ; referential competence when s/he negotiates wages on a basis including taxes or free of taxes (corresponding to French concepts of "salaire brut" or "salaire net") ; sociocultural competence when the learner has to decide whether s/he should apologies or justify her/himself, when Catherine arrives late at her rendezvous ; whether s/he should accept answering some questions or reject them, etc.

Could not it be argued that this type of simulation is too remote from a real human dialogue, since the learner's oral productions cannot be recognized by the system and the learner is not given the allowance of creating original chunks of discourses (either oral or written) ? One traditional way of responding to this argument is to apologies for the current limitations of computing techniques. A speech recognizer (not yet available with such constraints of use) would not be enough; nor would the connection with a parser, because the pedagogical aim here is not to focus on form. Thus, in order to accept learner's free utterances the environment should include a full Natural Language Processor which handles dialogues, i.e. recognizes the learner's action and intentions. Would that be a priority for such dialogues where the learner has only a limited range of initiatives?

In fact the discrepancy between a real human dialogue and the system-learner interaction may be seen as a positive point. An actual interview, even restricted to a situation where the applicant speaks in his/her mother tongue, requires instant decisions which have definitive implications, and a permanent control of linguistic and paralinguistic signs in a stressing situation. In such hypermedia environments cognitive overloads are avoided. Breaks are welcomed to let the learner analyses at his/her pace what is going on (the recruiter's goals and gestures), to carefully prepare his/her recording, to access resources for fully comprehending detailed points, etc.

Obviously the feedback given to the learner on his/her performance could be improved. When designing simulations we had originally planned to let the learner evaluate her/himself first, before displaying the system's evaluation and to give detailed explanations of his/her most important choices that would have had the most important consequences over his/her marks. But time constraints reduced our ambitions.

\section{GENERAL FEATURES OF THE ARE SOFTWARE}

Anthropomorphic overviews of learning environments commonly adopt three perspectives: those of the domain expert, of the pedagogue and of the learner. We follow here this convenient break-down.

\subsection{LINGUISTIC AND DOMAIN EXPERTISE}

In communicative and LSP approaches the question of production of authentic materials has often been raised (Bérard 1991; Hutchison \& Waters 1987). Reasons for insuring authenticity are: 
- The motivation of the learner. When the communicative approach is mainly advocated as a pretext for supporting the learner's interest in studying the target language (Canale \& Swain 1980), providing actual documents is essential. This is even more so the case within the LSP philosophy, where the word 'actual' should qualify the linguistic materials and the task contents.

- The development of autonomous learning. Making the learner practice strategies specific to the treatment of authentic documents helps her/him reinvest his/her skills in finding information and managing tasks in professional settings.

- The quality of the Input. Particularly audio and video actual materials expose the learner to rich inputs, for which certain linguistic aspects have not yet been precisely analyzed but are considered as necessary to be taught.

Assuming authentic documents are needed, then a team which is developing CALL multimedia software faces several problems: what kinds of authenticity (actual or simulated) should be guaranteed in different activities? How will corresponding materials be collected and/or produced; are specific backgrounds required?

Large storage facilities like CD-ROMs, videodiscs are frequently presented as the panacea for providing learners with actual multimedia data. Indeed interesting programs, often restricted to textual activities (like Autolire ${ }^{4}$ ), have been built on top of collected raw materials. However such materials only supplement one part of the data that are to be used in interactive task-oriented software. Members of the Athena project at the MIT institute (Murray \& al 1988) distinguish two kinds of material that can be put on large devices: the narrative and the documentary. One of their software, "A la rencontre de Philippe" has recently been released. Their aims are very close to ours, i.e. "the ability to use a second language to perform or have others perform certain actions, and the ability to understand language in a culturally authentic and task-centered situation." They invented a plot in which the learner meets a young man named Philippe who is about to be thrown out of his apartment by his girlfriend and who needs help in patching up his romance or finding another place to live. One videodisc is documentary. It provides textual, audio and video data on the quartier St Gervais in Paris where the learner will have to find a flat. The team has not collected existing documents but produced them from scratch (which means recording and shooting in Paris). The main part of the software that in charge of managing the plot is in the other videodisc, the narrative one.

"A la Recherche d'un Emploi" is organized in a slightly different way. Units of this module cover a full CD-ROM. We used two kinds of authentic materials. The first kind, which corresponds to the minor part of our linguistic data, is made of actual (unabridged or extracted) textual documents collected and disseminated in every unit in order: to offer complementary activities (like extracts of job announcements published in the press which are relevant to Catherine's or Gérard's profile) ; or to provide further examples for drills (such as some letters of application in Unit 2 which illustrate more situations than the ones strictly relevant to our characters) ; or to bring extra socio-cultural information. The second kind of what we call 'authentic material' has been created by ourselves. It represents the major part of the linguistic data of the software, i.e. all its audio and video resources and part of its textual materials. For the sake of authenticity and coherence of our story we decided to build them

\footnotetext{
${ }^{4}$ Software reviewed in ReCALL, vol. 6, n 1 , May 1994, pp 55-56.
} 
out of real situations. The two characters, we named for our own purposes Catherine and Gérard, do exist ${ }^{5}$. Details of their profiles and successive endeavors when submitting applications are nearly all actual. For scripting the interview, we needed to refer not only to books dedicated to applicants but also to recruiters. Lastly some actors who participated in the project have a part time job in training unemployed people from various status to find a job and thus our actors often play the role of recruiters. Such constraints were also imposed by our aim, which was to closely reflect the cultural habits of the target country, whose importance in LSP has been mentioned in the first part of the paper. Every country differs in its way of recruiting staff. Even in a target country, foreign companies which have kept their original way of managing, like IBM in France, base their recruiting procedures on a different culture.

As we have recalled, authentic materials guarantee the quality of the Input. But if we want the Input to become an 'Intake' for the learner, the richness and the level of difficulty of the materials often need to be filtered. Part of this simplification process is achieved by authors when scripting materials and designing activities: in video-based activities (out of the two simulations) the system first displays the film without subtitles; afterwards it breaks down the Input by displaying the full text, besides the video. The simplification process is also under the learner's control. When first looking at the video only, s/he can use the video palette to stop the film and repeat any sequence. Then, when studying the text, s/he can select any part of it to replay the corresponding video sequence. These simple techniques permit repetition and redundancy (oral and written presentations) of the Input, which we know from SLA research on the "foreigner talk" are part of the necessary conditions that help the learner process the Input.

\subsection{PEDAgOGICAL PRINCIPLES}

Our basic pedagogic approach is to encourage the acquisition of the ability to use language to do things. Thus over the whole course the target language, French, has been used as the only language of communication between the computer and the learner. Consequently, the activities we have created not only encourage the acquisition of 'real-world' competencies, but also require the learner to use the target language in order to meet the immediate goal of undertaking any activity.

"A la Recherche d'un Emploi" and all CAMILLE courseware have been designed to support the study of the target language. The notion of support is crucial here. CAMILLE is a learning not a teaching resource. The objective was not the creation of software to 'teach' French, but the construction of an environment that would provide the learner with all the tools and information, short of a live teacher, and that they might need to undertake a specific level of course in French. One consequence, already mentioned, is the integration of books/resources with the textbook (the proper course) on the same desktop (to continue the metaphor). Another consequence is the mode of its use and of its integration into a whole curriculum. If we put forward the learner's autonomy and self-training, however, we do not reject the supervision of live trainers. Our software, for example, aims at covering two units of the DEFL. Training institutions provide intensive courses over several months to prepare the whole DEFL. An appropriate integration would be that the institution dispatches part of

\footnotetext{
5 In the final unit (Unit 5) we inform the learner that the two persons eventually found a job in a position very close to what we had imagined ; these events happened on the conclusion of our implementation.
} 
the training to the learner herself/himself and only has a remote supervision of his/her work with "A la Recherche d'un Emploi", some study being undertaken either indoors or at work, or at home. A limited supervision is still preferable, at least because some activities cannot be fully assessed: for example, none of the CALL techniques permit to correct the pronunciation of the learner's records. Effectiveness of such integration ${ }^{6}$ will be measured as planned in our next period of evaluation.

A drawback of the so-called learner's autonomy is that it leaves too many decisions to the learner and underestimates the role of pedagogical intervention. Here we tried to make explicit our pedagogical decisions. Progress among units and, inside a unit, among activities are constrained by the coherence of tasks and subtasks. When breaking down a task we also have taken care of grading the linguistic difficulties: in Unit 2 which focuses on writing formal letters and CVs we classified textual activities from identification of data to constrained composition. Other pedagogical decisions partly constraint the way of performing a sequence of sub-activities. Let us come back, for example, to the organization of a video-based activity, already mentioned in the previous section. After the film is displayed without subtitles, then follows a global comprehension test without any video. The full text only appears in a third stage, beside the video screen; the learner can then study the text at ease; lastly comes a detailed comprehension test.

According to our basic pedagogic principle, we make an important distinction between activities proper and drills. As a general rule, drills tend to be limited repetitive activities designed to provide practice with some very particular skill. For example, "A la Recherche d'un Emploi" (ARE) contains drills that allow the learner to practice his/her oral recognition of numbers or his/her remembering of lexical items. Most of these drills are located in the reference books, not in the textbook. Activities proper, on the other hand, are less limited in scope and demand a response from the learner that is more reflective than reflexive. They are all concentrated in the textbook.

Partly because the team adopted a deliberately eclectic approach to the creation of learning activities, it is difficult to list the full range of possibilities that are available to the learner within ARE. There are 33 learning activities (50 if we count all the possible variants). We have taken care to balance activities by involving both oral, written, listening, and speaking skills. The next section illustrate the way the learner can link up various activities.

\subsection{LEARNER'S INTERACTION AND ASSESSMENT}

What does a typical working session look like? Let us suppose the learner is not using the software for the first time; then s/he will have a disk containing his/her private stack ${ }^{7}$ which stores records of his/her previous performances and another stack where s/he may have stored some notes. Once s/he has copied these stacks on the main disk and typed his/her name, work can start. When s/he clicks on the reference button 'SUIVI', a tree appears which displays the whole hierarchical structure of the software from the root/module down to the fifty leaves/sub activities. The learner checks what s/he had already achieved in previous sessions; then s/he comes back to the textbook where s/he selects a unit and an activity either

\footnotetext{
6 The mode of integration discussed here is obviously not the only possible one. But just asserting, without evaluation, that a software can be used as a stand alone, wherever that suits the learner, is certainly a tempting commercial argument but not a reliable one.

7 Stacks are files where data and programs (scripts) are stored in hypertexts.
} 
because of its content or its linguistic content (the latter information is given in a pop-up window which is linked to the unit icon). When s/he enters into the selected activity, oral instructions are given. Complementary information is accessible by using the INSTRUCTIONS button. Let us assume that s/he chooses the activity 4 of Unit 2 "Understanding a CV". In the first sub activity of activity 4, by using the mouse ${ }^{8} \mathrm{~s} /$ he will have to seek after and copy differential items between two CVs (referential discrepancies are requested; the learner should not select items which are simply phrased in different ways). When a word is unclear, s/he selects it, directly if it is a "hot word", or indirectly by accessing the LEXICON book if not. When the user feels that $\mathrm{s} /$ he should remember its definition, then s/he copy it in his/her note-pad located in the 'NOTES' book. Being satisfied with his/her answers, or just bored (!), s/he clicks the 'CORRECTION' button of the textbook. The system presents indications about what went wrong or right, or possible variants and asks the user whether s/he prefers to have another go or get the full correction. In the latter case, full corrections appear besides his/her answers. When s/he comes out of this first sub activity of activity 4, the system prompts her/him to go on to the next one. But the user prefers to give up for this time and switches to the phone unit in order to practice some listening comprehension. Eventually, before closing the session, s/he wants to have a look at her performances. S/he clicks on 'SUIVI' and has access for every activity to his/her performances on the first try, the previous and the current one. S/he then prints his/her notepads, quits the system and saves his/her new personal information on disc.

This snapshot of a working session may have shown the reader what kind of interactivity we are looking for (the question of whether learners actually do behave in that way will be experimentally measured). This combination of immediate unsolicited feedback along with detailed summary information is typical of the texture of the interaction between user and machine throughout CAMILLE programs. On the one hand, the computer provides prompts, whether questions or feedback, that seek to provoke responses from the user; and, on the other, there are a whole range of facilities through which the user can seek a response from the computer. Consequently, the overall human-computer interaction within CAMILLE may be described as 'mixed initiative'. It is not simply a matter of responding mechanically to computer prompts or of freely wandering through the riches of a language. Instead inputs from both user and machine are interwoven in a 'dialogue', the details of which cannot be said to have been pre-programmed by the original authors. This 'dialogic' is fundamental to the design of advanced computer-aided language learning environments.

The reader may also have noticed that the reference book 'SUIVI' does not provide the learner with a real assessment ${ }^{9}$. It gives feedback of the quality and quantity of the learner's work and performances and of his/her progress, when activities have been accomplished several times. We imagine the latter situation to be the exception, not the rule, because there are so many possible different activities that the learner may avoid repetitions ... and this remark also partly explains why performance recordings cannot be used as a valuable

${ }^{8}$ Mouse and headphones are used in all activities, the microphone in most of them. The keyboard is compulsory in only one activity.

9 To avoid any confusion between the terms "assessment" and "evaluation", we, following Nunan's advises (1988, p 184), reserve "assessment" for the measure of the new abilities of the learner which can be achieved by simply assembling information, and the word "evaluation" for the whole procedure that attempt to certify the effectiveness of the software/course procedure which includes a decision making-process on the development of the software. 
assessment. The quality of the user's work is calculated on extent of the answers and thus is mostly a product measure. It reflects the results of the learner's activity not of his/her process. Only simulations can really evaluate the learner's process, i.e. the way s/he performed a task, either by explicit marking in the interview activity, as discussed in section 3.2 , or more indirectly in the telephone simulation, where s/he realizes at the end whether s/he has been able or not to make an appointment with the recruiter, depending on the selected answers, but where no marking is provided. There is a third type of (limited) feedback on the learner's work with respects to his/her oral recordings. Obviously we, at present, cannot automatically diagnose oral productions. By recording them and offering the possibility in the 'SUIVI' stack to replay them, the system can only allow the learner to evaluate her/himself or let the trainer make an off-line diagnosis. Rationales for giving feedback of the user's performances are twofold: it is a support for the learner's motivation and a certification of the amount of work undertaken, either for her/himself or for the trainer. In a self-training situation this information needs to be supplied. As regards companies which pay for a language training, they want to know to which extent their employees have at least achieved their workload and often require that sneaking devices should be included in software. To overcome this contentious way of appreciating the learner's involvement, we decided that we would make no distinction between the learner and the trainer. Both can access to the same reports. The only difference being that the trainer has access to all the learner's reports.

With regard to the CALL literature, it is often claimed that software developers should build assessment tests. It is however a difficult matter with such large-scale software we are considering. Firstly, we have showed that performance measures (which not all CALL programs provide) cannot be confused with assessment. Secondly many researchers, who support the communicative approach, think that assessment cannot be reduced to linguistic knowledge testing (Lussier 1992). Authors' courseware should not only evaluate knowledge but also evaluate the skills to communicate in specific situations. It implies developing a new piece of courseware which in many respects resembles a learning activity, i.e. to gather listening, reading, speaking and writing activities with all kinds of media previously used. Even if we left aside the fact that a safe assessment should only be undertaken after the learner has practiced several kinds of LSP activities (i.e. has used the 'selling act' module in our case), we should develop an extra-large piece of software, which must be included in the original CD and will seriously aggravate the workload. To bypass this problem, we plan to design a non-computer-based assessment test in the summative software evaluation phase (see section 6).

At present 'A la Recherche d'un Emploi' only offers an extra unit (unit 5) called in a somewhat confusing way 'BILAN'. Each of its four activities has topics which refer respectively to the contents of the four previous units (presentation, letters and CVs, telephone and interview). They do not include any video-based work. This is not an assessment test, but is worth practicing because reusing skills and knowledge in other contexts may help remembering and refinement. 
Are resources an extra or a necessity in a communicative-oriented CALL environments? Answers to this question are of interest to CALL designers and developers. If what we called 'reference books' in section 3.1, i.e. grammar, lexicon, functions and cultural resources, are optional, then CALL authors can forget them, or promise to include them in the next version of their system, or only include some of them as an extra marketing argument. If we think they are mandatory, then it is going to weigh down the development process.

Before bringing forward the rationale of a positive answer to the question, we give an overview of our resources books, because some of their features will be referred to in the following discussion.

\subsection{RESOURCES IN ARE}

Resources are strongly interconnected with the various facets of the linguistic competence, as described in section 2: grammar, lexicon, and function are purely linguistic whereas the fourth resource, the 'culture book', gathers socio-cultural information on France and information relevant to the specific purpose learning:

- The cultural book encompasses four main topics: studies in France (an overview of the whole curriculum, the different kinds of degrees, etc.), work in France and Europe (economic sectors, work lengths, wages, and socio-professional categories), unemployment in France and Europe (who are the unemployed? Figures, national comparisons, and the national agency, ANPE, etc.), telecommunications (How to make a phone call in/from France? What is the Minitel? Etc.). The knowledge base has been drawn out of authentic data, which for the sake of clarity are presented in charts and graphics and linked to textual information.

- The function book contains speech acts or notional-functional categories relating to the domain of social-interactions: informing, proposing, rejecting, requiring, opening/closing a meeting, etc. Unlike the way it is often described in FLE ${ }^{10}$ manuals, we distinguish registers (oral and written contexts, social contexts), and give the grammatical structure of lexical phrases.

- The grammar book. Thanks to the modularity of hypertext we could directly plug in the grammar developed by our English partners in the basic-level French course. We explained that we are not focusing on grammar and that learners are supposed to have a rather large grammatical knowledge before using ARE. Nevertheless, we should have extended the initial grammar with respect to the specific contents of the software. But lack of time, forbade it!

- the lexicon book assembles a dictionary and a set of lexical networks on such topics as employing and dismissing people, work, salary, training, and company. Since the structure of this book is a little unusual we will detail it hereafter.

The aim of the lexicon is to describe the lexical field characteristic of the domain. We circumscribed the set of words by selecting abbreviations, words, and compounds which frequently occurred in our scripts and have semantic relationships to the domain or task. We

10 FLE is the acronym of "Français Langue Etrangère". The abbreviation is the equivalent for French of the socalled EFL/ESL (English as a Foreign or Second Language) ones. 
have taken care to balance word registers (oral, written, formal, informal, and colloquial) in order to approximate the variety that is found in the competence of natives. The dictionary is a set of lexemes: words belonging to the same root are gathered on the same page (like "apprendre, apprenti, apprentissage"). Every lexical item has a definition (simply written, as in the Collins COBUILD), examples, and a grammatical structure (mainly for verbs). We used hypertextual facilities to elicit grammatical information, by displaying extra windows or by accessing the grammar book, to extend explanations around some words by accessing the culture book, etc.

The second part of the lexicon, the set of networks complements the dictionary, i.e. displays relationships between words. There are three types of networks: the hierarchical type, which displays homonymous links, the antonymous type, and the synonymous one, which makes a distinction between the (almost) strict synonymy, the intersective and the inclusive ones. Figure 4 provides an example of the graphical representation of a synonym type network: note the circles which circumscribe words that have the same meaning; other words may be linked to a set of words (in a circle) or to isolated words. When the learner clicks on a node, s/he access the lexical entry of the dictionary. Edges are labelled with icons that correspond to the type of the semantic link. When the mouse crosses over icons, a popup window shows the difference of meaning between both nodes of the edge. Lastly, colours divide the network into three areas according to the formal, informal, or colloquial registers.

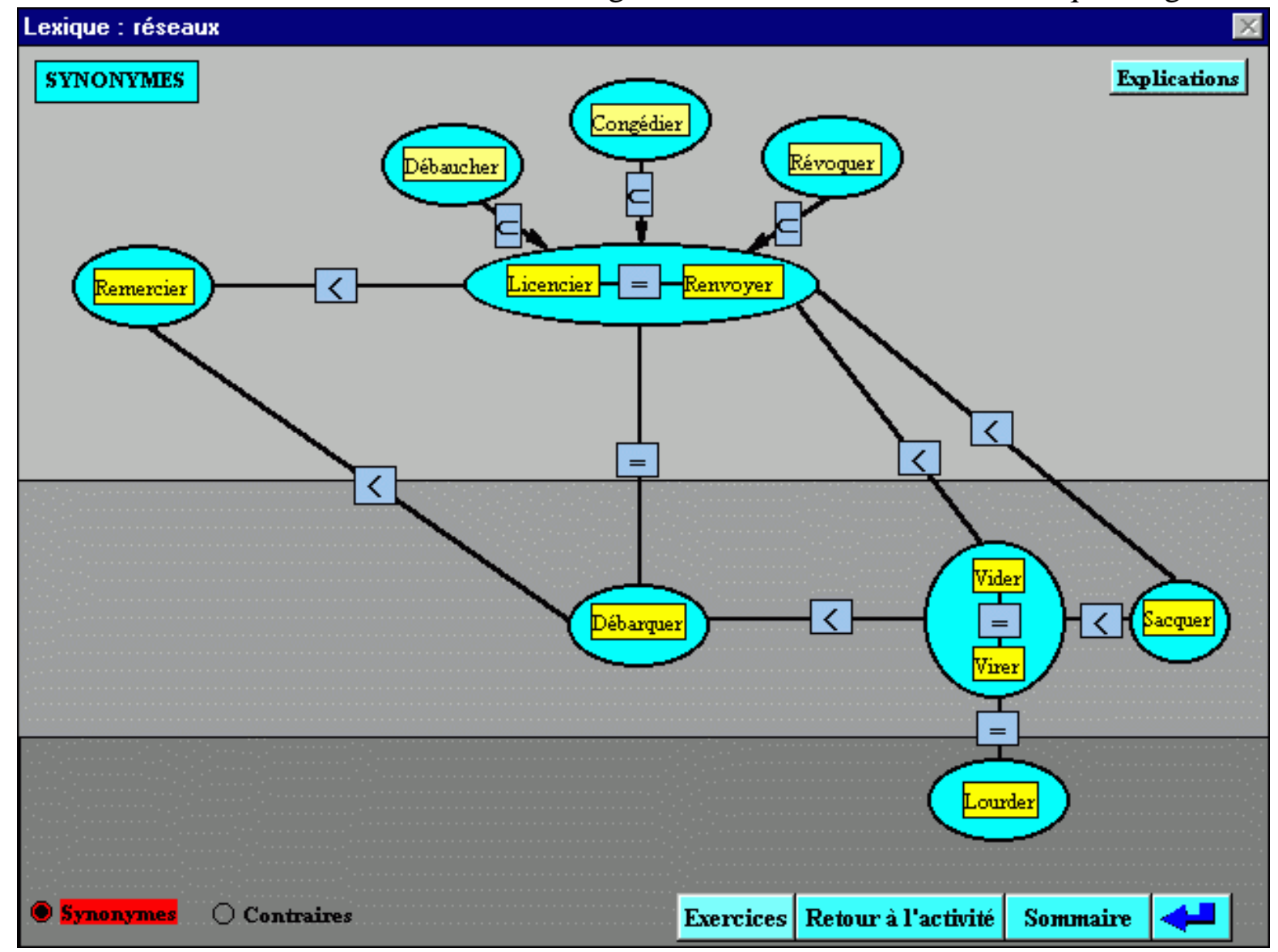

Figure 4: A partitioned lexical network build around the semantic field of dismissal. After the user has crossed over an icon, which labels an edge, a pop-up window appears (top-right part of the screen) and explains the difference of meaning between both nodes of the edge.

Thanks to hypertext facilities and linguistic research, it is now possible to break down the linear description of words found in most dictionaries, i.e. to always present a word: 
- As a set of elements extracted from various sets which belongs to different contexts (a word may be an element of a derivational family of the dictionary, an element appearing in several networks, and an item of information in the culture book). We give easy access from one type of presentation of one word to another.

- As having a meaning that can mainly be differentially defined within relationships with other words.

This approach is advocated as being more efficient in vocabulary learning on pedagogical and psycholinguistic grounds (Carter \& McCarthy 1988). Several CALL systems focus their research on such topics (see as examples (Goodfellow 1993; Chanier \& al 1994)). To enhance memorization, we have added lexical drills in the lexicon book.

The drawback of this method is the time taken to achieve deep linguistic descriptions. It can only be undertaken on a restricted lexical field, as we said, but this field is precisely the one in which learner's progress is most expected. At present only 300 lexical entries are included. We expect the forthcoming formative evaluation (see next section) to tell us what learners actually use and what is lacking.

\subsection{WHY RESOURCES ARE NECESSARY}

We will distinguish direct and indirect needs of resources in CALL environments, and more specifically in large-scale communicative-based ones.

A direct need appears when the learner lacks a piece of information to correctly and/or easily achieve an activity: without mentioning the necessity of providing lexical helps, many other situations may occur. For example, if the learner is not aware of the French way of calculating salaries, s/he may not succeed in his/her negotiation during the interview in unit 4 (should s/he negotiate it on a free of taxes basis or should taxes be included? Should specific social rights be considered?). In the classroom, the learner can address the teacher to obtain information and the teacher may have prepared beforehand a set of documents to allow the learner to practice searching strategies. In ARE the learner will find the relevant information and, even more, an extra drill on the calculation of salary? It is provided as a resource, not as a system aid: we do not want to disturb the learner when s/he is working on an activity by adding extra buttons on the screen. Instead we prefer to encourage the learning by adding an element of discovery. We have sign-posted access to resources but most of the time we do not offer strictly direct accesses.

An indirect need for resources occurs when we want to extend or to fix (i.e., support memory) the learner's knowledge after the completion of activity-based practices. We have previously stressed the difference between activities and drills, consequently we distribute knowledge and practice between the textbook and the references ones. Second language pedagogues often emphasize this second step of the classroom work. For example, if we consider the teaching of socio-cultural knowledge, Zarate (1986) recalls the importance of the cultural folder ("dossier de civilisation") that should be prepared by the teacher and correspond to the following characteristics: the folder is dedicated to advanced learners; it is a collection of authentic documents, is organized around a thematic axis, and is designed to update the learner's knowledge about a question. These characteristics neatly fit in with our working hypotheses in ARE. If communicative-based CALL software are designed to support autonomous learning, then such knowledge should be integrated. 
We listed some major pedagogical reasons for making resources available for the learner, to supply either direct or indirect needs. But should resources be electronically based? And should they be included in the CALL package or be external? There are numerous motives for urging CALL authors to develop resources (and also to convince sponsors that resources should be taken into account in the schedule). We only give a brief of them here:

- The principle software and resources are intertwined in several ways: a large part of the information is closely related (linguistically and pragmatically); resources can support complementary types of practices and varying them enhance CALL efficiency.

- Autonomy goes hand in hand with flexibility in space (software delivered on standard platforms can be used at work or at home) and in time. Consequently, we cannot expect the learner to carry a full library of books with him.

- External electronic resources are either expensive, non-existent or inappropriate.

- If some external resources were available we would still face the problem of integrating them so as to avoid learner's cognitive overload.

On short/middle term, CALL authors may expect notional-functional grammar packages to be available, packages which could be integrated as spelling checkers are in word processors. As regards lexical resources, at present, nothing can be found that could be realistically integrated ${ }^{11}$. But, fortunately, an extensive linguistic coverage is not a strict necessity.

Is it worth lengthily discussing resources while we ignore if learners will actually use them? In fact it is part of our work plan to try and find that out: the learner's behavior in direct-resources-need situations will be observed during the formative evaluation, whereas learner's indirect-needs will be artificially created (like teachers do) by pre and post-tests during the summative evaluation.

\section{THE CURRICULUM PERSPECTIVE}

In sections 3, 4 and 5 we explained the content of module 1, "A la Recherche d'un Emploi", and discussed general issues common to LSP hypermedia programs. We expect module 1 and the following module 2, "the Selling Act", to represent a full course, referred to as "Travailler en France", that will help learners to meet a significant part of the proficiency required in French degrees (cf. section 2.2). Consequently, we would like in this section to raise issues relating to the curriculum level: the dynamic process consisting of the course design, the course implementation, and the course evaluation. Since our work is a subpart of CAMILLE, we have to elicit relationships with the international project before coming back to our specific topic. Figure 5 illustrates time overlaps between points which we address in this section.

11 As far as we know, there is only one large-scale network-based lexicon, WORDNET ; but it is in English and should be connected to a traditional dictionary. Traditional electronic monolingual dictionaries are awfully expensive (but CDs supports are cheap !). Concerning French, the situation is even worse: there exist no monolingual learner dictionary, even on paper ! The "Français Fondamental" designed for a large audience of second language learners is outdated. Now, as a learner of French you are supposed to be either a child and use the "Robert pour enfant", or a literate and use dictionaries for natives. 


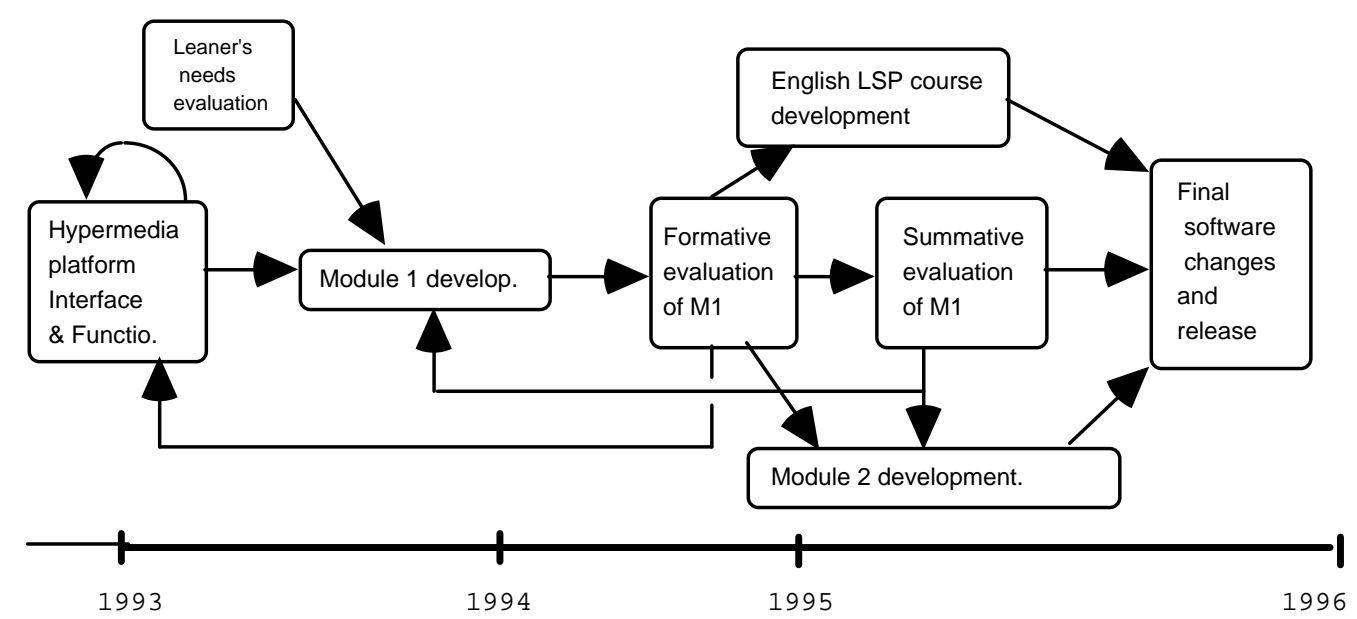

Figure 5: Actual software development process of LSP courses in CAMILLE. See figure 1 for details of a module development.

\subsection{MULTINATIONAL PRODUCTION IN CAMILLE}

The CAMILLE project aims at conducting a large-scale experiment touching upon issues arising from both pedagogical and software engineering viewpoints. From a pedagogical viewpoint, hypermedia technologies are often presented as an opportunity to enhance language learning. Although these factors are often assumed to play an important role in the acquisition process, as yet there have been no large-scale experiments based on their use. The CAMILLE project offers an opportunity to undertake such an examination in a multicultural environment. From a software engineering viewpoint, hypermedia programming tools are often recommended as an opportunity to speed up courseware development, and therefore make CAL a realistic complement for training learners in and out of the academic world. But production of courseware on hypermedia also dramatically increases the number of qualifications required and up to now our experience in re-using modules of software, shared knowledge for large-scale software is still very limited. Again, the work undertaken in the CAMILLE project should help to understand better the problems involved in transnational courseware development (see figure 7).

As is no doubt obvious from the preceding sections, the development of multimedia learning resources requires a wider range of skills and expertise than any individual can realistically be expected to possess. Consequently, the establishment of teams of developers would seem to be a sine qua non condition for effective multimedia courseware production. Furthermore, in the field of CALL, it seems likely that such teams will also be multinational. For example, if audio and video materials are to be genuine, they must be produced by native speakers and preferably by native speakers in situ in the target language environment. This can, of course, be achieved by taking a film crew and group of native speakers to their country of origin and producing the data. However, it is much easier and more efficient to have this production work done by groups of people who are permanently resident in the country of origin and this is what is being done in the CAMILLE project. Teams have been established in France, Holland, Spain and England each of which provides linguistic realia in their own language for the others to use in exploiting the CAMILLE platform to produce language learning resources. However, the setting up of such teams of multinational collaborators creates its own problems; problems that can be discussed under the headings of 
communication issues and technical issues (see (Ingraham \& al 1994) for further details). We now focus on international inputs and outputs of the French LSP courseware development process.

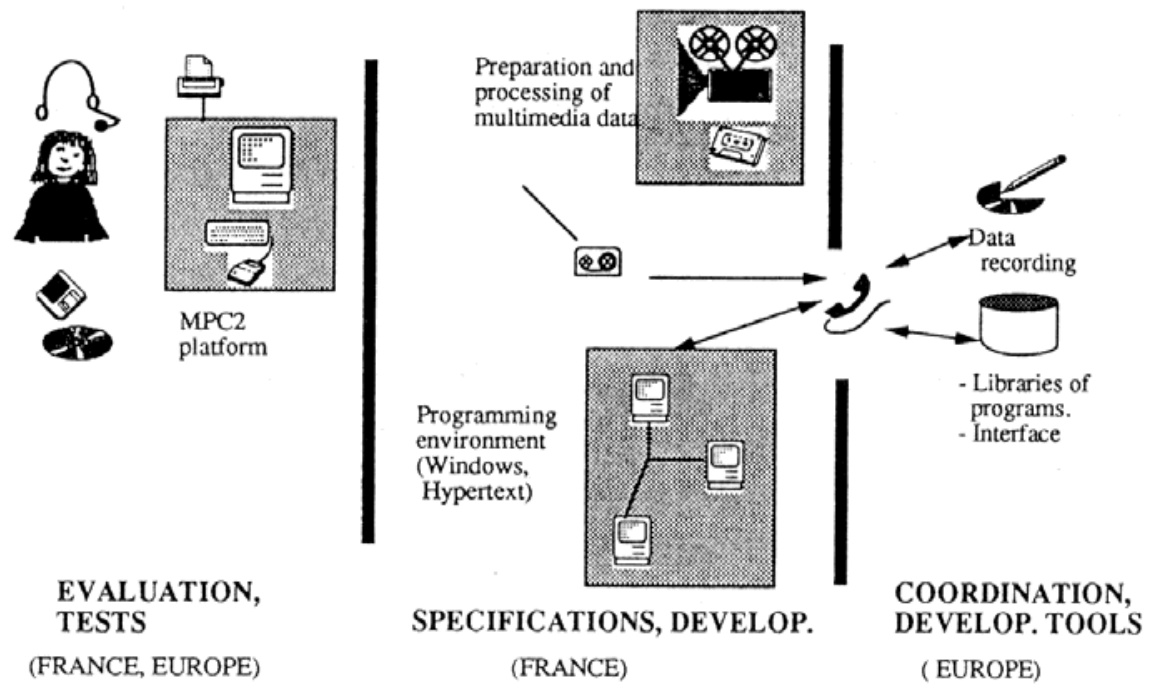

Figure 7: Trans-national collaboration for the development of the French LSP courseware within the CAMILLE project.

Initial inputs are twofold: firstly, our English partners developed FranceInteractive in 1991/92, a French beginner-level hypermedia software whose template has been reused by the consortium and adapted to LSP purposes; secondly we also reused the English software and hardware platform and modified it to meet the international standard MPC2. The multimedia PC platforms consists of a PC computer (486SX, 25 MHZ) with a 8 Mo memory, a VGA video-screen, a 160 Mo hard disc, a CD-ROM player (300 Ko/s), a soundcard, the Windows software, including its multimedia extensions. It is a minimal requirement to play full motion video. We chose the hypertext Toolbook as the programming language. Meeting the standards is very important if we want to encourage autonomous learning (the computing environment has to be easily accessible and fairly cheap). For the same reason, we selected the $\mathrm{CD}$ as the appropriate storing device. But on the other hand it is also very constraining for developers: at present other types of computing platforms would have been more advanced for running and developing multimedia data; the PC video files format for CD is constantly changing and will represent an everlasting extra workload till actual good standards are agreed upon. We also benefit from a permanent input during the implementation phase: thanks to the collaborative framework adopted by the consortium we have regular technical meetings where pieces of code are shared and developmental problems are discussed.

Reusability is the expected output of our work. "A la Recherche d'un Emploi" is the first experience of the CAMILLE Consortium in developing hypermedia LSP courses. We expect 
our architecture and working hypotheses to be portable across languages. Next year will confirm (or not) this assertion, when "Travailler en France" is evaluated in different countries and the development of the 'English for Specific Purposes' course starts.

Needless to say that without such a collaborative framework adopted in CAMILLE, we could not have met the project deadlines.

\subsection{PLANNING PROCESS: THE LEARNER'S NEEDS}

The learner's needs are the input of every LSP curriculum design, as we recalled in section 2. But this term is also somewhat vague. As Hutchison and Waters (1987, pp 53-63) we will decompose the needs analysis into target and learning (not learner) needs. The analysis of target situation needs is concerned with knowing what the learners will have to do in the target situation and with language use; whereas analysis of learning needs should reveal how people learn to do what they do with language (Why are the learners taking the course? how do they learn? what resources are available? who are the learners? where and when will the LSP course take place?). At the beginning of the project, we had only imprecise ideas of what such needs could be. We explain hereafter how we tried to find some answers.

In section 3 we mentioned two kinds of end-users of our LSP course: students of economics/business departments and employees of SME. They are not unrelated: the intersection between both target audiences is not empty (some of the students will become members of the marketing/commercial staff of SME, however the SME's employees potentially interested in language training also include technicians and secretaries), but training conditions, motivations, etc. are much different. We undertook a two-step pre-study (Refaa \& Pothier 1993). Firstly, we interviewed local experts, i.e. an academic language trainer of the Economic School, and executives of public institutions that assist enterprises (particularly SMEs) to export or advise them on management and trading. Some of the latter are also responsible for the organization of language training. Secondly, we selected 36 SMEs which have a significant proportion of their activities in export. Nine of them accepted to be interviewed. We prepared a questionnaire based on four topics:

- To what extent is language proficiency important in their international business?

- What are the most important target situations? For which category of staff and which channel of communication (speech, letters, phone, etc.)?

- How is language training planned?

- What kind of resources do they use in language training?

Out of these interviews we drew out the most important target situations that we have incorporated as tasks into our two modules. Briefly, the most relevant information, that helped us to estimate learning needs was: that language proficiency is a recruitment criteria only for marketing and sales engineers/inspectors ; that as firms develop their export, other categories of staff (sometimes even all) become concerned with various aspects of language proficiency, which can then lead to internal promotions ; that enterprises almost never plan any training in any domain ; that when they urgently need to train people in language, they never do it internally but always address public institutions, such as we mentioned, or specialized language training institutions ; that language training consists of attending a course or, in a minor proportion, of practicing through the phone ; that a major drawback of 
training periods is that they disturb work ; and that computers are widely used in all sorts of tasks, but never as a learning support ${ }^{12}$.

Our small-scale inquiry is consistent with what European studies made in enterprises reveal. Obviously, needs analysis and planning of language training are major problems, addressed by several LINGUA projects (Springer 1993), but these are not our direct concern. We may induce from our study that there is a place for autonomous learning with large-scale LSP software. Training institutions seem unavoidable intermediaries at the first stage. In this case autonomous learning is supervised by trainers, and may be done at work and, from there, at home.

\subsection{IMPLEMENTATION PROCESS}

When implementing module 1 , we followed the procedure illustrated in figure 1 . Not surprisingly, our multidisciplinary team faced two types of problems: technical and linguistic.

We will not discuss at this point the software engineering aspect of the work: how to manage large quantities of audio-video data; how to organize programs in a modular way within the hypertext framework (which is unfortunately not object-oriented); or how to share technical and exercise codes with our partners. Developing these discussions would necessitate another paper. On the whole we met two unexpected difficulties, which disturbed our planning: one, aforementioned, concerned the video formats on CDs; another when implementing the learner's follow-up program (cf. section 4.3). The former may disappear in the near future, but not the second. Such a "trifling" problem (as it is often qualified) indeed becomes a tricky one when software gather widely ranging activities and multimedia data.

Hutchinson and Waters said (1987, p 106) "material writing is one of the most characteristic features of English for Specific Purpose in practice". Truly, the same comment is relevant to LSP CALL materials. Not being specialized in the target situation, we have to meet professional people, interview them, and pre-shoot videos. By pre-shoot, we refer to a process consisting in shooting a film in real settings, then scripting the scenario, giving the video and script to actors before the final shoot happens. To illustrate the obstacles that the production of authentic materials incurs, we could compare the CALL situation with that of LSP teachers. Let us suppose that one teacher is in charge of the development of a language course in a scientific department, where he usually works. Another teacher is sent outside of his customary institution (let us say for training employees to handle a plant whose documentation and savoir-faire are only available in a foreign language). Our situation is closer to the latter: learners needs must generally be evaluated beforehand, actual materials and backgrounds are not to be elaborated within your usual institutional environment.

One advantage of not being in a specialized institution is that authors escape the internal pressures that may lead to the production of over-specialized materials, as sometimes happens in language business courses for example !

\subsection{EVALUATION PROCESS}

It is often claimed with regard to the CAL literature that evaluation should be part of every project workload. Although it is much less frequently put into practice, it is nevertheless true

12 Not surprisingly the language learning situation in the Economics School is the same as in other academic schools: in France students forget at university the limited language skills acquired in secondary schools, mainly because the number of hours attributed to language courses is ridiculously low ! 
that working hypotheses, which have been asserted, need to be (at least partly) proved for two essential reasons. Firstly, before the end of the development cycle of the software, experiments can help to check that learners will actually use the material as it is intended to be used, that they will use it all, and that no major gaps or negative interferences will appear in the interface. Secondly, at the end of the development process, other experiments should measure to what extent learning has been effective with respects to the initial pedagogic aims. Hence two kinds of evaluation need to be set up, the formative and the summative ones.

Evaluation is a difficult issue and we are, at present, only beginning to specify it. So here we will only give its outlines. "A la Recherche d'un Emploi" will be tested abroad, within our partners' institutions and on other external sites, just as we will test some of our partners' products. But we will only comment on evaluation that we will manage and where we would have direct control of the various parameters.

The evaluation site is a local language training institution, whose audience is mainly composed of foreign adults studying French, intensively, full-time over several months, for academic or professional motives. They usually prepare the DELF or even DALF (for more advanced learners) degrees.

The formative evaluation (Ollier \& al 1995) involved a limited number of subjects. It has been an intensive experiment for the learners, over a short time period. The experimenter has always been present. Every activity and resource have been tested. Data have been collected through audio and video recordings, hand written notes, questionnaires and interviews. Major findings reported will be integrated in modules 1 and 2, before the end of the year.

The summative evaluation, planned for June 1995, will be of a much different type. But before it happens, a pre and a post-test will be designed with some of the teachers of the institution according to the principles previously mentioned: it should measure the different aspects of the communicative competence. It will be used as the learner's assessment procedure and will encourage the acquisition of socio-cultural knowledge. Part of these paper-based documents may, later on, be joint to the software for release. Then, the evaluation will be supervised by teachers over a longer time period. Several groups of subjects will be set up. We do not intend to have any group working without the CALL environment. Former experiments reported in the literature, which took the opposite view, appear somewhat unfair, biased and may have had teachers feel as if they were challenged.

Once the summative phase is achieved, the overall results will be published.

\section{CONCLUSION}

It is now well accepted among researchers and practitioners in Second Language Acquisition that being proficient in a language means acquiring a satisfactory communicative competence. Learning a language for specific purposes is a very good situation in which to apply the communicative approach, because training interweaves linguistic and professional goals, on one hand, and knowledge and savoir-faire, on the other hand. Thanks to CALL research progresses and recent technical and software engineering methods developments, it is now possible to create large-scale hypermedia interactive courseware. If we immerse the software in a problem-solving approach, then the learner is able to focus on tasks that are mediated through language, and where success or failure correspond to whether or not these tasks are performed. 
"A la Recherche d'un Emploi", the first half of the French for Specific Purposes courseware we developed within the European CAMILLE project, is one of the early example of such task-based and problem-solving oriented software. On the course of its presentation, we raised several general issues which concern such type of software and, more widely, large-scale hypermedia CALL one: how the content is determined by the characteristics of the task ; how simulation activities immerse the learner in real-life problemsolving situations, yet situations where s/he keeps control ; why authenticity is a major pedagogical requirement and what it consists of ; why the core of the software should be organized around proper activities, whereas drills should be moved to the resources ; why resources, which reflect the various aspects of the communicative competence, are necessary ; what learner-system interactivity looks like within a hypertextual environment ; why the follow-up procedures of the learner's performances are important but should not be confused with learner's assessment.

Having presented the CALL environment, we turned our attention to the curriculum perspective. We explained our methodology of work: starting from the planning phase where the learner's needs are defined by determining the target situations and the learning ones, where also the computing platform is fixed; moving then to the implementation phase where we mention where the bulk of the work has been; finishing with the evaluation phase where we outlined the formative and summative experiments that we are specifying at present.

Our team achieved the development of "A la Recherche d'un Emploi" within nearly one year. Before being too conclusive, we obviously need to measure experimentally its effectiveness in real learning situations. However the discussion on what should be the content and organization of hypermedia environments for LSP within a communicative approach can start. Minimal conditions for enabling CALL teams to achieve such development are at hand: available hypermedia techniques; reliable SLA and CALL results of studies; a multidisciplinary team, integrated in an international framework.

Through this paper, we also expect to open a discussion on the integration of the curriculum perspective within the CALL environment developmental process. This is a fairly new subject. Several LINGUA projects are currently focusing on needs analysis for enterprises, and several LINGUA/DELTA projects are discussing at length methods of evaluation of CALL software. The CALL community may expect useful guidelines and recommendations. However the study of the constraints of simultaneous integration of the three phases will be missed. It is still an open research question that very few projects have addressed $^{13}$.

\section{ACKNOWLEDGEMENTS}

We would like to thank Maguy Pothier, Paul Lotin, Jérôme Ollier and Mokrane Refaa, from Clermont University, who have participated to the specification and development of "A la Recherche d'un Emploi". We are also much indebted to our partners of the LINGUA/CAMILLE project, and more specifically to Bruce Ingraham and Chris Emery,

13 The British TELL consortium (Thomson 1994) handles specifications, implementation and evaluation of CALL materials in different sites. It is an interesting new kind of collaborative framework. Since it is an ongoing work no extensive literature has yet been published. 
from Teesside University, who took the initiative in the project and set up the hypermedia platform.

\section{REFERENCES}

Allwright D. \& Bailey K.M. (1991) : Focus on the Language Classroom. Cambridge University Press.

Bérard E. (1991) : L'approche communicative : Théories et pratiques. CLE International : Paris.

Brumfit C. \& Johnson K. (1979) (eds.): The Communicative Approach to Language Teaching. Oxford University Press.

Bialystok E. (1990): Communication strategies: a psychological analysis of second-language use. Basil Blackwell: Oxford.

Canale M. \& Swain M. (1980): "Theoretical bases of communicative approaches to second language teaching and testing". Applied Linguistics, vol. 1 (1), p 28.

Carter R., McCarthy M. (1988): Vocabulary and Language Teaching. Longman: London.

Chanier T. (ed.) (1994): Special Issue on Language Learning. Journal of Artificial Intelligence in Education. (JAIE) . To appear in 1994.

Chanier T., Cointe N., Fouqueré C., Issac F. (1994): "Acquisition des Expressions Lexicales en Langue Seconde : Environnement Informatique et Modélisation". "La locution: entre lexique, syntaxe et pragmatique" Workshop, organised by the CREDIF (Centre de Recherche et d'Etude pour la Diffusion du français).

Chanier, T., Pengelly, M., Twidale, M.\& Self, J. (1992): "Conceptual Modelling in Error Analysis in ComputerAssisted Language Learning Systems". In Intelligent Tutoring Systems for Second-Language Learning, Swartz, M. \& Yazdani, M. (eds.). New York: Springer-Verlag, 125-150.

Goodfellow R. (1993): "CALL for vocabulary, requirements, theory and design". Computer Assisted Language learning (CALL), vol. 6 (2). pp 99-122.

Hamburger H. (1994): "Foreign Language Immersion: Science, Practice and a System". To appear in (Chanier 94).

Hallyday M.A.K. (1973) : "Towards a sociological semantics" in (Brumfit \& Johnson 79), pp 27-46. Excerpts from a 1973 publication.

Hatch E. (1992): Discourse and Language Education. Cambridge University Press.

Hutchinson T., Waters A. (1987): English for Specific Purposes. A learning-centred approach. Cambridge University Press.

Hymes D. H. (1971) : "On communicative competence" in (Brumfit \& Johnson 79), pp 5-26. Excerpts from a 1971 publication.

Ingraham B., Chanier T., Emery C. (1994): "CAMILLE, a European project to develop language training for different purposes, in various languages on a common hypermedia framework". Computers and Education., vol. 23, 1/2, pp 107-115.

Johnson K. (1979): "Communicative Approaches and Communicative Processes" in (Brumfit \& Johson 1979), pp 192-205.

La Passardière B. \& Baron G.L. (eds.) (1991): Hypermédias et Apprentissages. INRP: Paris.

Laurillard D. (1991): "Principles for Computer-based Software Design for Language Learning". Computer Assisted Language Learning, vol. 4 (3), pp 141-152.

Lehmann D. (1993) : Objectifs spécifiques en langue étrangère : les programmes en question. Hachette : Paris.

Lussier D. (1992): Evaluer les apprentissages dans une approche communicative. Hachette: Paris.

McAleese R. \& Green C. (1990): Hypertext : state of the art. Intellect : Oxford.

Melrose R. (1991) : The Communicative Syllabus: A systemic-Functional Approach to Language Teaching. Pinter Publishers : London.

Moirand S. (1982): Enseigner à communiquer en langue étrangère. Hachette: Paris.

Murray J.H., Morgenstern D., Furstenberg G. (1988): "The Athena Language Project: Design issues for the Next Generation of Computer-Based Language-Learning Tools". In Modern Technologies in Foreign Language Education: Applications and Projects. Smith W.F. (ed.). American Council of the Teaching of Foreign Languages. pp 97-117.

Nunan D. (1988) : The Learner-Centred Curriculum. : A study in second language teaching. Cambridge University Press.

Nunan D.(1992): Research Methods in Language Learning. Cambridge University Press.

O'Malley J.M, Chamot A.U.(1990): Learning Strategies in second language acquisition. Cambridge University Press. 
Ollier J., Chanier T., Pothier \& Lotin P. (1995) : The formative evaluation of CAMILLE-"A la recherche d'un emploi". Internal report of the CAMILLE/LINGUA project. Université Clermont 2. January.

Porcher L. (1990) : " L'évaluation des apprentissages en langue étrangère". Etudes de Linguistique Appliquée , $\mathrm{n}^{\circ}$ 80. pp.5-36.

Rakotobe-Darricades I. (1992): "Le français des affaires, contenu et enseignement". Les Français Professionnels, LINX journal 27 (2). Institut linguistique de Nanterre, Paris X University. pp 93-101.

Refaa M., Pothier M. (1993): "L'apport des technologies de l'information hypermedia aux entreprises: cas de la gestion de l'apprentissage des langues des affaires". Internal report of the CAMILLE/LINGUA project. University of Clermont 2.

Springer C. (1993): "L'évaluation dans les entreprises: vers une recherche de la qualité". Le Français dans le Monde. Special issue on evaluation, August-Septembre. EDICEF: Paris.

Tarone E. \& Yule G. (1989) : Focus on the Language Learner. Oxford University Press.

Thomson J. (1994): "TELL into the mainstream curriculum". TWENTE Workshop on Language Technology. Twente University: Holland. pp 93-99.

Zarate G. (1986): Enseigner une culture étrangère. Hachette: Paris.

\section{ANNEXES}

Translation of the dialogue between recruiter and applicant, represented in Figure 3. 'A' represents the applicant where ' $\mathrm{R}$ ' represents the recruiter.

R3 : So then, why is it that you left your last employment ? You were made redundant I believe?

A3.1: - Yes, that's right. The reshuffling of the company meant that all the machines, and therefore those who operated them, were to work (24hours) around the clock. As for me, I've got 2 small children that I want to see grow up, and not be working while they sleep and asleep while they're awake.

A3.2 : - I got the feeling that I wasn't really moving on, that I was always doing the same things on the same machines. Only the machine were changing, not me. I wanted something more creative, more demanding. So, when I was offered this placement in as technician in the research offices building I jumped at the chance !.

R4: Yes, and the atmosphere at work in your last company can't have been too good, very domineering no doubt ?

A4.1: Tell me about it ! The bosses didn't even know themselves how to work the new machines. Many a time I had to show others what to do.

A4.2 : Oh well, you know I think all companies have their own problems.

R5 : So how long have you been looking for work ? 